\title{
INCONSTITUCIONALIDADE DA EXIGÊNCIA DE CEM SALÁRIOS MÍNIMOS PARA CONSTITUIÇÃO DA EIRELI FACE À VIOLAÇÃO DOS PRINCÍPIOS DA LIVRE INICIATIVA E DA PRESERVAÇÃO DA EMPRESA
}

\section{UNCONSTITUTIONALITY RELATED TO THE OBLIGATION TO CONTRIBUTE A HUNDRED MINIMUM WAGES FOR EIRELI CONSTITUTION DUE TO THE VIOLATION OF THE PRINCIPLES OF FREE ENTERPRISE AND COMPANY PRESERVATION}

\author{
${ }^{1}$ Milena Zampieri Sellmann \\ ${ }^{2}$ Suhel Sarhan Junior
}

\section{RESUMO}

Atualmente a atividade empresarial destaca-se pelo cumprimento de suas funções sociais, não mais pelo aspecto individualista de geração de riquezas. Por isso, deve a legislação protege-la criando incentivos ao seu nascimento, oportunidades e benefícios à sua continuidade. Para fomentar a instituição de empresas individuais, a Lei n. 12.441/11 instituiu a EIRELI, todavia, estabeleceu como condição de constituição um aporte mínimo de cem salários mínimos. Essa exigência viola os princípios da livre iniciativa e da preservação da empresa, o que macula a norma que a impõe de inconstitucionalidade, tema, inclusive, objeto de ADI.

Palavras-chave: Eireli, Aporte de cem salários mínimos, Princípio da livre iniciativa, Princípio da preservação da empresa

\begin{abstract}
Currently the entrepreneurial activity stands out for the fulfillment of their social functions, not anymore by the individualistic aspect of wealth generation. Therefore, the law should protect it by creating incentives for its creation, opportunities and benefits for its continuity. To foster the creation of individual companies, the law n. 12.441/11 instituted the EIRELI, however, established as a condition for its constitution a minimum contribution of one hundred minimum wages. This requirement violates the principles of free enterprise and of company preservation, what maculate the norm that imposes unconstitutional, topic ADI object.
\end{abstract}

Keywords: Eireli, Contribution of a hundred minimum wages, Principle of free enterprise, Principle of company preservation

\footnotetext{
${ }^{1}$ Doutora em Direito Tributário pela Pontifícia Universidade Católica de São Paulo - PUC SP, São Paulo, SP. (Brasil). Coordenadora do Curso de Direito e Professora de Direito Tributário do Centro Universitário Salesiano de São Paulo - U. E. de Lorena, São Paulo, SP.(Brasil). E-mail: milenasellmann@ hotmail.com.

${ }^{2}$ Mestra em Direito pelo Centro Universitário Salesiano São Paulo, - UNISAL, São Paulo, SP. (Brasil). Professora da Faculdade de Direito Prof. Damásio de Jesus - FDDJ, São Paulo, SP. (Brasil). E-mail: suheljunior@gmail.com.
} 


\section{INTRODUÇÃO}

A empresa, tal como encarada na atualidade, não mais é vista sob a ótica do individualismo, de fonte de acúmulo de riquezas para quem as detém e de exploração para quem delas depende. No mundo contemporâneo cada vez mais ela ganha destaque pelo cumprimento de suas funções sociais, tais como geração de postos de trabalho, arrecadação tributária e contribuição para a manutenção do meio ambiente.

Por isso, o Direito Empresarial moderno, respaldado por princípios constitucionais como o da livre iniciativa, pauta-se na construção de legislações que incentivem o início e a continuidade da atividade empresarial, por entender que sua manutenção é de extrema importância para a econômica e para o bem estar de toda a população.

A fim de incentivar a criação de empresas individuais, a Lei n. 12.441/11, que alterou o Código Civil, instituiu a EIRELI (Empresa Individual de Responsabilidade Limitada), com o objetivo de não permitir que as dívidas da pessoa jurídica pudessem, em regra, atacar o patrimônio pessoal do titular empresário, equiparando, desta maneira, às garantias conferidas ao Direito Societário.

Todavia, contraditória foi a inserção da exigência de capital mínimo de cem salários para sua constituição, previsão que se encontra desconexa com o princípio da livre iniciativa, que comina que a legislação deve fomentar a abertura e a continuidade das empresas e, também, com o princípio da preservação da empresa, que prevê que a atividade empresarial deve ser incentivada desde se seu início, e cujo tema já é objeto de debate em uma Ação Direta de Inconstitucionalidade (ADI 4637).

Assim, o presente artigo visa num primeiro momento discorrer sobre a empresa, a atividade empresarial e a EIRELI para num plano posterior analisar os enunciados do Conselho da Justiça Federal sobre as dúvidas suscitadas sobre este tipo empresarial, para, por fim, defender a inconstitucionalidade da exigência do capital mínimo para sua formação por violação do principio constitucional da livre iniciativa e, também, do princípio da preservação da empresa.

A pesquisa se baseará, principalmente, pela análise doutrinária e jurisprudencial sobre o tema, de forma que o mesmo se justifica na medida em que é um assunto atual, pendente de apreciação pelo Supremo Tribunal Federal e que influenciará na vida econômica de milhares de brasileiros. 


\section{EMPRESA}

Os estudiosos do Direito Empresarial sempre encontraram dificuldades para se chegar a um conceito que definisse "a empresa", pois ela não pode ser confundida com seu exercente (empresário ou sociedade empresária), tampouco como a organização dos bens que a compõe (estabelecimento empresarial).

Posto isto, importante frisar a diferença desses conceitos, uma vez que empresário e sociedade empresária são os exercentes da atividade empresarial, ou seja, sujeitos de direito titulares da empresa.

De outra monta, quando há a reunião por eles de elementos corpóreos e incorpóreos para o desenvolvimento de sua atividade, como, por exemplo, a aquisição de maquinário, ponto, balcão para a montagem de uma pastelaria, a isso se dá o nome de estabelecimento empresarial, estudado pelo Código Civil nos artigos 1142 a 1149.

Assim, quando adentramos num galpão ou em um local em que a atividade é exercida, está-se diante do estabelecimento empresarial e não propriamente da empresa.

Gladston Mamede prepondera que:

É preciso compreender a empresa como um ente autônomo, que não se confunde com sua base patrimonial (complexo organizado de bens, nos termos do artigo 1142, do Código Civil), nem se confunde com o seu titular, que será o empresário ou a sociedade empresária (da mesma forma que esta não se confunde com seus sócios, nem com as pessoas de seus administradores). (2013, p.28).

Conclui-se, dessa maneira, que a empresa muito embora seja equivocadamente confundida por muitos com seu aspecto patrimonial (estabelecimento empresarial) ou mesmo com seus exercentes (empresário individual ou sociedade empresária) é um ente autônomo, formada por seus exercentes e cuja finalidade é o desenvolvimento de uma atividade econômica, que produzirá bens ou serviços, que só se tornam viáveis em virtude da aquisição de bens específicos que viabilizem a atividade (estabelecimento empresarial).

A empresa é a organização de meios materiais e imateriais, incluindo pessoas e procedimentos, para a consecução de determinado objeto, com a finalidade de obter vantagens econômicas apropriáveis: o lucro que remunera aqueles que investiram na formação do capital empresarial. A empresa, na sua qualidade de organização, é um conjunto de partes com funções específicas, constituída artificialmente pelo engenho humano, com a finalidade de otimizar a atuação econômica, produzindo riquezas. (MAMEDE, 2013, p. 29). 
A dificuldade de se conceituar a empresa decorre da própria ausência de sua definição legal, de forma que a legislação brasileira, assim como a Italiana, se preocupou em definir o seu exercente (empresário ou sociedade empresária), furtando-se da definição do ente.

Numa tentativa de definição do que seja empresa, Alberto Asquini a define de acordo com suas funções e funcionalidades, criando o que ficou conhecido como Teoria Poliédrica da Empresa, a qual foi amplamente estudada e divulgada no Brasil por Waldirio Bulgarelli (1995, p. 124)

Para Asquini a empresa deve ser estudada em seus quatro aspectos básicos, quais sejam:

1. Subjetivo: preocupa-se em estudar a pessoa que exerce a empresa, seja ela natural (empresário individual pessoa física) ou jurídica (EIRELI ou sociedade empresária). O Código Civil brasileiro estuda o exercente da atividade nos artigos 966 e seguintes;

2. Objetivo: preocupa-se em estudar o Estabelecimento Empresarial, ou seja, as coisas utilizadas pelo empresário ou pela sociedade empresária no exercício de sua atividade. $\mathrm{O}$ aspecto objetivo da empresa é tradado nos artigos 1142 a 1149, do Código Civil;

3. Aspecto funcional: refere-se à atividade do empresário ou da sociedade, em seu dia-a-dia, sendo entendida como o exercício da atividade. Nessa parte são estudados a escrituração de livros, contabilidade, balanço, exclusão de sócios, dentre outros assuntos que se encontram esparsos no Código Civil e em legislações específicas;

4. Aspecto corporativo ou institucional: estuda os colaboradores da empresa, aqueles que dedicam esforços para a consecução da atividade, bem como o caráter institucional da empresa frente a sociedade (p.113-114, 1996).

Inexistindo definição legal de empresa, mas sim a de seu titular, o empresário, passaram os doutrinadores a buscar um conceito jurídico e sua natureza no âmbito do Direito. Entre estes se destaca Alberto Asquini, com sua teoria poliédrica da empresa, que mereceu profundo e completo estudo de juristas brasileiros, dos quais se notabilizou Waldirio Bulgarelli com seu monumental Tratado de Direito Empresarial, de inigualável valor científico até hoje não superado. (NEGRÃO, 2012, p. 64).

\section{ATIVIDADE EMPRESARIAL}

A atividade empresarial, por premissa, encontra proteção e amparo na Constituição da República de 1988, a qual garante o estimulo ao início, a continuidade e ao desenvolvimento 
das empresas, por se entender que elas se mostram como imprescindíveis para a manutenção da economia brasileira.

Nesse sentido, já no primeiro artigo da CRFB, em seu inciso IV consagra como fundamento da República a livre iniciativa e, de forma, complementar, o título VII, artigos 170 e seguintes, abordam a defesa e a proteção da ordem econômica, a fim de regular de maneira geral a atividade empresária, mostrando-se o constituinte preocupado com o seu bom desenvolvimento.

A atividade empresarial no contexto atual deve ser desenvolvida com a finalidade de promover, também, a justiça social e de forma a preocupar-se com valores que extrapolam os interesses das minorias dominantes, a fim de que não haja concentração de poderes econômicos.

Não se vê mais no caráter de liberalismo como liberdade absoluta, gerando concentração de riquezas e poderes sem se preocupar com o social e com o coletivo.

O professor José Afonso da Silva destaca a importância dessa atividade e de sua proteção constitucional para a manutenção da econômica:

A liberdade de iniciativa envolve a liberdade de indústria e comercio ou liberdade de empresa e a liberdade de contrato. Consta do art. 170, como um dos seus esteios da ordem econômica, assim como de seu parágrafo único, que assegura a todos o livre exercício de qualquer atividade econômica, independentemente de autorização de órgãos públicos, salvo casos previstos em lei.

É certamente o princípio básico do liberalismo econômico. Surgiu como um aspecto da luta dos agentes econômicos para libertar-se dos vínculos que sobre eles recaiam por herança, seja do período feudal, seja dos princípios do mercantilismo.

No início, e durante o século passado até a Primeira Grande Guerra, a liberdade de iniciativa econômica significava garantia aos proprietários da possibilidade de usar e trocar seus bens; garantia, portanto, do caráter absoluto da propriedade; garantia da autonomia jurídica e, por isso, garantia aos sujeitos da possibilidade de regular suas relações de modo que tivessem por mais conveniente; garantia a cada um para desenvolver livremente a atividade escolhida.

Ora, a evolução das relações de produção e a necessidade de propiciar melhores condições de vida aos trabalhadores, bem como o mau uso dessa liberdade e a falácia da 'harmonia natural dos interesses' do Estado liberal, fizeram surgir mecanismos de condicionamento da iniciativa privada em busca da realização da justiça social, de sorte que texto supratranscrito do art. 170, parágrafo único, sujeito aos ditames da lei, há de ser entendido no contexto de uma Constituição preocupada com a justiça social e com o bem estar coletivo. (2011, p. 795-796). 
Atualmente em nosso país a atividade empresarial pode ser exercida sob duas modalidades: de forma individual, quando o empresário sozinho decide montar sua própria empresa e a exercê-la sem o concurso de nenhum outro sócio; de forma coletiva, quando duas ou mais pessoas se unem para explorar a atividade empresarial.

Por motivos fáticos e econômicos, a maioria das empresas é exercida coletivamente, considerando-se uma sociedade empresária.

O ser-humano, em todas as atividades que desenvolve em sua vida, pretende praticálas com o concurso e o auxílio de outras pessoas. É assim quando se pretende viajar, para educar os filhos, para ir ao cinema entre outras atividades.

Por isso, é inerente a todos o ímpeto de querer se agrupar com outros para desenvolver praticamente qualquer atividade do dia-dia, não sendo esse sentimento diferente, portanto, com relação à atividade empresarial.

Em regra, sentimo-nos mais fortes para exercer a empresa quando estamos em união, pois contamos com o auxilio de outros sócios. Esse é o motivo fático que nos leva a ter a maioria de empresas sendo exercidas na modalidade coletiva.

O motivo econômico se apresenta em consonância com o sistema capitalista acirrado e globalizado. Pensar que uma empresa individual, exercida por apenas uma pessoa, possa crescer e se tornar grande nesse contexto pontual da economia mundial é, no mínimo, utópico. Por isso, as empresas individuais ficaram adstritas aos pequenos negócios, que não demandam grandes quantias em dinheiro, tampouco grandes complexidades para o seu exercício.

Amador Paes de Almeida salienta que:

Del tal processo evolutivo resultaria a conjugação de esforços que consubstanciariam a forma primitiva de sociedade, assim considerada a reunião de duas ou mais pessoas, com o propósito de combinar esforços e bens, com objetivo de repartir entre si os proveitos auferidos. Na união dessas forças, pois, encontramos as primeiras manifestações da sociedade, conquanto, obviamente, bem distanciada dos dias atuais.

De início simples comunhão circunstancial, aos poucos foi assumindo proporções e contornos próprios, numa progressiva sistematização de regras e princípios. Inspirada na natureza associativa do ser humano, haveria a sociedade de obter, em muito pouco tempo, excelentes resultados na produção, com sensíveis alterações na economia dos povos. (2012, p. 25-26)

Assim, percebe-se claramente que a maioria das empresas na atualidade é exercida na modalidade coletiva. 
Todavia, com a finalidade de dar as mesmas proteções conferidas às sociedades, o Código Civil Brasileiro foi alterado no ano de 2012, por meio da Lei n. 12.441/11, a qual institui a Empresa Individual de Responsabilidade Limitada.

\section{EMPRESA INDIVIDUAL DE RESPONSABILIDADE LIMITADA}

Até o advento da EIRELI, aqueles que optassem por ser empresários individuais, mesmo que registrados na Junta Comercial, não possuíam personalidade jurídica, o que se demonstrava um fato muito gravoso, haja vista que sempre possuíam responsabilidade ilimitada, ou seja, respondiam com todo seu patrimônio pessoal pelas dívidas contraídas no exercício da empresa. Tanto é verdade que em momento algum o artigo 44, do CC previa o empresário individual dotado de personalidade jurídica. Sempre foi, portanto, a própria pessoa física exercendo a empresa em seu próprio nome e com responsabilidade ilimitada.

Por outro lado, quando se optava por abrir a empresa em sociedade, esta sempre ganhou personalidade jurídica com seu registro (Art. 44, do CC), que se diferenciava das pessoas físicas dos sócios que a exerciam e, dependendo do tipo societário escolhido, como, por exemplo, a sociedade limitada, além de ter personalidade jurídica, não permite em regra que o patrimônio pessoal dos sócios seja atacado por dívidas sociais.

Claramente a legislação da forma como se apresentava protegia a empresa exercida em caráter coletiva e sancionava o empresário individual, o que gerava muitas constituições de sociedades limitadas de fachada.

Sendo assim, muitas discussões se prolongaram na doutrina e na jurisprudência sobre o porquê do ordenamento jurídico brasileiro não prever a figura do empresário individual com responsabilidade limitada, pois, como dito, a ausência deste instituto estimulou inúmeras criações de sociedades limitadas de "fachada", as quais se apresentam, em regra, da seguinte maneira: presença de dois sócios, sendo um com quase a totalidade do capital social e o outro com uma pequena parcela, não atuando em nenhum ato decisório, tampouco administrativo da sociedade, apenas emprestando seu nome ao outro sócio para que esse pudesse montar uma pessoa jurídica e conseguir a proteção patrimonial, exercendo, assim, a empresa com maiores garantias.

Por isso, já era hora de acabar com essa situação e conferir a mesma proteção patrimonial para aqueles que querem exercer a atividade empresarial de forma singular, sem precisar constituir uma sociedade de fachada apenas para terem seus bens pessoais protegidos.

Nesse cenário é aprovada a Lei n. 12.441/11, que altera alguns artigos do Diploma 
Civil e institui o chamado "Empresário Individual de Responsabilidade Limitada".

Referida lei insere o artigo 980-A no Código Civil, que passa a viger com a seguinte redação:

Art. 980-A. A empresa individual de responsabilidade limitada será constituída por uma única pessoa titular da totalidade do capital social devidamente integralizado, que não será inferior a 100 (cem) vezes o maior salário-mínimo vigente no País.

$\S 1^{\circ} \mathrm{O}$ nome empresarial deverá ser formado pela inclusão da expressão "EIRELI" após a firma ou a denominação social da empresa individual de responsabilidade limitada.

$\S 2^{\circ}$ A pessoa natural que constituir empresa individual de responsabilidade limitada somente poderá figurar em uma única empresa dessa modalidade.

$\S 3^{\circ}$ A empresa individual de responsabilidade limitada também poderá resultar da concentração das quotas de outra modalidade societária num único sócio, independentemente das razões que motivaram tal concentração.

$\S 5^{\circ}$ Poderá ser atribuída à empresa individual de responsabilidade limitada constituída para a prestação de serviços de qualquer natureza a remuneração decorrente da cessão de direitos patrimoniais de autor ou de imagem, nome, marca ou voz de que seja detentor o titular da pessoa jurídica, vinculados à atividade profissional.

$\S 6^{\circ}$ Aplicam-se à empresa individual de responsabilidade limitada, no que couber, as regras previstas para as sociedades limitadas.

Outra alteração importante que passa a valer para o empresário individual de responsabilidade limitada diz respeito ao nome empresarial a ser adotado por ele.

Prevê a lei a possibilidade de utilização das modalidades firma ou denominação, acrescidos, ao final, em ambos os casos, da expressão "EIRELI", ao contrário do empresário individual de responsabilidade ilimitada que deve, necessariamente, utilizar a modalidade firma.

O empresário individual de responsabilidade limitada não pode figurar em duas empresas desse gênero, podendo constituir apenas uma.

O artigo 44 do Código Civil, que estipula as espécies de pessoas jurídicas também foi alterado com o advento dessa legislação, na medida em que a ele foi acrescido o inciso VI, que prevê uma nova figura de personalidade jurídica, qual seja: o empresário individual de responsabilidade limitada. Veja que até então, o empresário individual de responsabilidade ilimitada tinha CNPJ para fins de tributação, mas não era considerado pessoa jurídica, tratavase da própria pessoa física exercendo a empresa em seu nome. 
No entanto, agora o empresário individual de responsabilidade limitada passa a ser uma pessoa jurídica distinta da pessoa física de seu exercente.

Por estar previsto em apenas um artigo do Código Civil, a EIRELI entrou em vigor com muitos questionamentos a serem respondidos, os quais foram devidamente analisados pelo Conselho da Justiça Federal, que editou os seguintes enunciados.

\subsection{ENUNCIADOS CJF}

Algumas omissões legislativas na introdução da EIRELI no ordenamento jurídico brasileiro fizeram com que fossem suscitadas algumas dúvidas sobre essa nova figura, as quais foram pacificadas pelo Conselho da Justiça Federal. São as principais:

A EIRELI pode ser constituída apenas por pessoa física (natural) ou também pode ser de propriedade de pessoa jurídica?

Enunciado $\mathrm{n}^{\circ} 468$ - A empresa individual de responsabilidade limitada só poderá ser constituída por pessoa natural.

A EIRELI é novo tipo societário ou novo tipo de empresa individual?

Enunciado $\mathrm{n}^{\mathrm{o}} 469$ - A empresa individual de responsabilidade limitada (EIRELI) não é sociedade, mas novo ente jurídico personificado.

Pode a Teoria da Desconsideração da Personalidade Jurídica ser aplicada à EIRELI?

Enunciado $n^{\circ} 470$ - O patrimônio da empresa individual de responsabilidade limitada responderá pelas dívidas da pessoa jurídica, não se confundindo com o patrimônio da pessoa natural que a constitui, sem prejuízo da aplicação do instituto da desconsideração da personalidade jurídica.

Em qual momento há a atribuição de personalidade jurídica para a EIRELI?

Enunciado $\mathrm{n}^{\mathrm{o}} 471$ - Os atos constitutivos da EIRELI devem ser arquivados no registro competente, para fins de aquisição de personalidade jurídica. A falta de arquivamento ou de registro de alterações dos atos constitutivos configura irregularidade superveniente.

Pode ser utilizada a expressão "social” para a designação das atividades da EIRELI?

Enunciado no 472 - É inadequada a utilização da expressão "social" para as empresas individuais de responsabilidade limitada. 


\subsection{EXIGÊNCIA DE CEM SALÁRIOS MÍNIMOS PARA CONSTITUIÇÃO}

De acordo com o caput do artigo 980-A, do CC, o empresário individual de responsabilidade limitada deverá, necessariamente, iniciar sua atividade com todo o capital social já integralizado, sendo que a quantia deve ser de, no mínimo, cem salários mínimos, o que pensamos ser uma monta considerável, principalmente para quem está começando seu negócio de forma individual, até porque, como visto anteriormente, em regra o empresário individual exerce pequenos negócios, não possuindo, na maioria das vezes, a quantia exigida para formar uma EIRELI.

A explicação para um aporte mínimo de cem salários mínimos no capital social se dá no fato da proteção aos credores, que não mais poderão buscar seu crédito no patrimônio pessoal do exercente da empresa, de modo que, por consequência, o patrimônio dessa empresa tenha que ter um lastro mínimo para saldar eventuais débitos.

Ao nosso ver, a lei acertou ao criar o empresário individual de responsabilidade limitada, visando acabar com a Sociedade Limitada de Fachada. Por outro lado, imputar a integralização imediata de, no mínimo, cem salários mínimos ao empresário individual é, ao menos, estimular a existência do empresário individual de responsabilidade limitada de "fachada" e explico por que.

As empresas com grande circulação de dinheiro e mercadoria são exercidas em forma de sociedade. Pois bem, quantos empresários individuais que irão iniciar sua atividade econômica possuem disponibilidade real e concreta de integralizar, de início, cem salários mínimos no capital da empresa? Resposta: Muito poucos. Ora, será empresário individual o trabalhador que talvez faça um curso técnico de cabeleireiro e quer se formalizar, abrindo seu salão; um jovem com anseio de montar seu próprio negócio, ainda de forma tímida, para vender cachorro quente em frente a uma faculdade, entre outros.

Por isso, imputar a eles a integralização mínima de cem salários mínimos é desarrazoado e vai de encontro ao princípio da livre iniciativa e também ao do princípio da preservação da empresa.

Assim, acreditamos que muitas empresas individuais surgirão na irregularidade, mencionando no contrato que integralizaram cem salários mínimos, pois papel aceita tudo, quando na verdade não possuirão esse lastro, apurando-se tal irregularidade posteriormente numa execução, o que poderá dar ensejo ao instituto da desconsideração da personalidade 
jurídica (artigo 50, do CC), o que consequentemente nos remeterá ao status quo, qual seja: empresário individual de responsabilidade ilimitada.

Discordamos do fato de que os credores devem possuir um lastro mínimo para sua garantia, até porque se assim o é, porque as sociedades limitadas não possuem um limite mínimo de capital social inicial previsto em lei, tampouco precisam os sócios integralizar de imediato as quotas que subscreveram? A resposta para essa celeuma não nos foi dada pelo legislador.

\subsection{PRINCÍPIO DA LIVRE INICIATIVA}

O art. 170, caput, da Constituição da República Federativa do Brasil traz como um dos princípios basilares da ordem econômica a Livre Iniciativa, segundo a qual o direito deve estimular a abertura de novas empresas, a fim de estimular a livre concorrência e ao empreendedorismo. A livre iniciativa também é considerada um fundamento da República, prevista no art. 1, inciso IV, da CRFB.

Todavia, causa-nos espanto a exigência da integralização de, no mínimo, cem salários para a Constituição da EIRELI, a qual flagrantemente viola o principio constitucional acima preconizado.

Ora, como dito, as empresas individuais hoje ficam restritas aos pequenos negócios, de forma que os médios e grandes empreendimentos empresariais se formarão como sociedade, pois precisarão do capital e da ajuda de outras pessoas.

Assim, imputar uma necessidade de integralização desta natureza a uma empresa pequena é, no mínimo, desestimular sua criação, pois a maioria não terá esta quantia de início.

Ademais, a sociedade limitada, que traz a mesma proteção patrimonial e que em regra é maior que a EIRELI não possui exigência de capital mínimo, o que demonstra também a violação a outro princípio constitucional, o da igualdade (art. 5, caput).

A integralização mínima para a EIRELI não causa repulsa somente à nós, tanto que há pendente de julgamento no Supremo Tribunal Federal a ADI n. 4637 (remetemos o leitor à

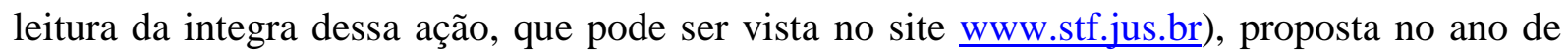
2012 pelo PPS (Partido Popular Socialista) e que está sob a relatoria do Ministro Gilmar Mendes. 
Referida peça pleiteia a declaração da inconstitucionalidade da exigência de capital mínimo para a EIRELI justamente por afrontar ao princípio da livre iniciativa e, também, pelo fato da indexação do capital se lastrear em salário mínimo.

\subsection{PRINCÍPIO DA PRESERVAÇÃO DA EMPRESA}

Como visto, por certo que a empresa se mostra como de suma importância para a manutenção da economia, possuindo como função social basilar a de geração de postos de trabalho, absorvendo a maior parte da mão de obra ativa do Brasil, pois atualmente a maioria dela está empregada no setor privado, nas empresas.

Por isso, a atividade empresária se mostra como importante fonte produtora de trabalho e, por consequência, importante fonte de consumo, pois quanto mais empresas existirem, mais empregos serão gerados e quanto mais empregos, mais consumidores dispostos a gastar e, assim, movimentar e fechar o ciclo das economias pautadas no sistema capitalista.

De acordo com esse cenário, em que a empresa se mostra como substancial fonte de sustento capitalista, a legislação brasileira irá protegê-la em alguns aspectos, sempre de maneira a criar incentivos ao seu nascimento, bem como dando oportunidades, benefícios e criando condições favoráveis para sua continuidade.

Com base nessa importância coletiva e social, nasce o principio da "Preservação da Empresa", segundo o qual, sempre que possível, o sistema jurídico deve trazer mecanismos que estimulem o início e facilitem a continuidade da atividade empresarial.

De acordo com a teoria do funcionalismo jurídico, de Norberto Bobbio, o Estado deve incentivar de forma positiva instituições e institutos que cumprem esse papel social, por ser o Estado um ente assistencialista. Dessa forma, deve-se criar normas e encorajamento e de incentivo a essas atividades.

(...) a respeito das medidas de encorajamento e desencorajamento, sob uma perspectiva funcional, as primeiras são utilizadas com o objetivo de mudança, enquanto que as medidas de desencorajamento são usadas com o objetivo de conservação social, de manutenção do status quo. Talvez por este motivo as técnicas de desencorajamento, notadamente as sanções negativas, ainda sejam dominantes na teoria geral do direito (BOBBIO, 2007, p.84).

O princípio da preservação da empresa ganha foco e importância com a mudança de visão da atividade empresarial, que deixa de ser contratualista para a proteção de interesses 
individuais (sócios e controladores) e passa a exercem função institucional, de interesse coletivo.

Para Fábio Ulhoa Coelho:

(...) no princípio da preservação da empresa, construído pelo moderno Direito Comercial, o valor básico prestigiado é o da conservação da atividade (e não do empresário, do estabelecimento ou de uma sociedade), em virtude da imensa gama de interesses que transcendem os dos donos do negócio e gravitam em torno da continuidade deste. (2008, p. 13).

Referido princípio não se encontra atualmente explicito em nenhum dispositivo de lei, corpo codificado ou de forma expressa em qualquer tipo de legislação que compõe o ordenamento jurídico brasileiro vigente, mas vem implícito em muitas legislações empresarialistas, em sua essência, tornando-se base de sua formação, de maneira que ele pode ser encontrado principalmente nas legislações.

Ademais, o Princípio da Preservação da Empresa, caso aprovado o PL n. 1572/2011, ainda em trâmite na Câmara dos Deputados, que prevê a criação de um novo Código Comercial, passará a prever de forma expressa a obediência do Direito a esse princípio (artigo 4 , inciso III).

André Luiz Santa Cruz Ramos dá destaque a diversos pontos em que a preservação da empresa é enfoque legislativo, principalmente relacionado ao direito recuperacional e ao societário, vejamos:

O objetivo primordial do processo falimentar, segundo o dispositivo ora em análise, é "promover o afastamento do devedor de suas atividades" visando a "preservar e otimizar a utilização produtiva dos bens, ativos e recursos produtivos, inclusive os intangíveis, da empresa". Aqui se destacam dois importantes princípios do Direito Falimentar moderno: (i) o princípio da preservação da empresa e (ii) o princípio da maximização dos ativos. (2011, p.516).

Ocorre que, muitas vezes, a ausência de affectio societatis pode estar restrita a determinado sócio, podendo a sociedade, portanto, continuar a existir sem ele. E mais salutar, nesses casos, excluir um sócio com quem os demais não querem mais manter relação social do que acabar com a própria relação societária. Essa e a solução mais condizente com o principio da preservação da empresa, tão caro a doutrina contemporânea do direito empresarial. (2011, p.223).

Não diferente é a jurisprudência pátria, que há muito vem reconhecendo em seus julgados a existência da importância de se preservar a empresa, principalmente ao proferir decisões relacionadas à continuidade da atividade empresária, como se observa a seguir: 
Comercial Recurso especial. Falência. Decreto-lei 7.661/45. Títulos de valor insignificante frente ao principio da preservação da empresa. Decreto de quebra. Descabimento. Precedentes. I. Nos termos da jurisprudência do STJ, "Apesar de o art. 1. ${ }^{\circ}$ do Decreto-lei n. ${ }^{\circ} 7.661 / 45$ ser omisso quanto ao valor do pedido, não e razoável, nem se coaduna com a sistemática do próprio Decreto, que valores insignificantes provoquem a quebra de uma empresa. Nessas circunstancias, ha de prevalecer o principio, também implícito naquele diploma, de preservação da empresa” (REsp 959695/SP, Relatora Ministra Nancy Andrighi, DJe 10/03/2009). Precedentes. II. Recurso especial não conhecido (REsp 598.881/SC, Rel. Min. Aldir Passarinho Junior, 4 a Turma, j. 15.12.2009, DJe 08.02.2010).

No caso em apreço, entenderam os julgadores que mesmo no caso de impontualidade (dívida) por parte da empresa, se de valor insignificante, não é plausível que se decrete sua quebra, em virtude da importância da continuidade da atividade empresarial.

Percebe-se, também, após leitura da ementa que, apesar da atual legislação que rege o procedimento falimentar datar de 2005 (Lei n. 11.101/05), mesmo em julgamento de casos que envolviam o antigo decreto-lei já se falava em preservação da atividade empresarial, sustentando ser de interesse social sua continuidade.

PROCESSO CIVIL. RECURSO ESPECIAL. AÇÃO DE FALÊNCIA
AJUIZADA SOB AÉGIDE DO DECRETO-LEI 7.661/1945.
IMPONTUALIDADE. DÉBITO DE VALORÍNFIMO. PRINCÍPIO DA
PRESERVAÇÃO DA EMPRESA. 1. O princípio da preservação da empresa
cumpre preceito da norma maior, refletindo, por conseguinte, a vontade do
poder constituinte originário, de modo que refoge à noção de razoabilidade a
possibilidade de valores inexpressivos provocarem a quebra da sociedade
comercial, em detrimento da satisfação de dívida que não ostenta valor
compatível com a repercussão socioeconômica da decretação da quebra. 2. A
decretação da falência, ainda que o pedido tenha sido formulado sob a
sistemática do Decreto-Lei 7.661/45, deve observar o valor mínimo exigido
pelo art. 94 da Lei 11.101/2005, privilegiando-se o princípio da preservação
da empresa. Precedentes. 3. Recurso especial não provido. (STJ - REsp:
1023172 SP 2008/0012014-0, Relator: Ministro LUIS FELIPE SALOMÃO,
Data de Julgamento: 19/04/2012, T4 - QUARTA TURMA, Data de
Publicação: DJe 15/05/2012).

No caso acima, tem-se mais um julgado proferido pelo Superior Tribunal de Justiça, que enfatiza de forma ainda mais clara a importância sócio - econômica da empresa, devendose preservá-la, mesmo em caso de débitos, ou seja, mesmo que esteja em situação de crise econômico-financeira, mas se ainda for viável, deverá a mesma ter sua quebra impedida.

COMERCIAL E PROCESSUAL CIVIL. PEDIDO DE FALÊNCIA. DECRETO-LEI $\mathrm{N}^{\circ}$ 7.661/45. VALOR ÍNFIMO. PRINCÍPIO DA PRESERVAÇÃO DA EMPRESA. INDEFERIMENTO. I. O Superior 
Tribunal de Justiça rechaça o pedido de falência como substitutivo de ação de cobrança de quantia ínfima, devendo-se prestigiar a continuidade das atividades comerciais, uma vez não caracterizada situação de insolvência, diante do princípio da preservação da empresa. II. "Após a Nova Lei de Falências (Lei 11.101/2005), não se decreta a falência fundada em crédito inferior a 40 (quarenta) salários mínimos da data do pedido de falência, devendo o art. $1^{\circ}$ do Decreto-lei 7.661/45 ser interpretado à luz dos critérios que levaram à edição da Nova Lei de Falências, entre os quais o princípio da preservação da empresa." (REsp 805624/MG, Rel. Min. Sidnei Beneti, Terceira Turma, unânime, DJe 21/08/2009). III. Recurso especial conhecido, mas desprovido. (STJ - REsp: 918399 SP 2007/0010237-6, Relator: Ministro ALDIR PASSARINHO JUNIOR, Data de Julgamento: 12/04/2011, T4 QUARTA TURMA, Data de Publicação: DJe 15/04/2011)

Portanto, percebe-se a importância da atividade empresarial, entendida atualmente como de interesse coletivo e de caráter institucional, para o cumprimento de sua função social.

Por isso, pensamos também que a exigência de cem salários para a constituição da EIRELI, além de inconstitucional, viola flagrantemente o principio norte do Direito Empresarial, qual seja: o da preservação da empresa.

Ora, exigir cem salários não fará com que as pessoas fiquem incentivadas a abertura de uma empresa, mas, sim, o contrário.

\section{CONCLUSÃO}

Partindo-se da premissa que o Estado Brasileiro pauta-se pela livre iniciativa e que o Direito Empresarial mostra-se como matéria que visa a preservar a atividade empresarial, criando mecanismos de incentivo e continuidade à ela, nota-se claramente que a EIRELI, tal como se apresenta em nosso Código Civil, deve ser alterada, a fim de não imputar o ônus de exigência de lastro mínimo para sua constituição, por ínfimo que seja o valor.

Trata-se de medida necessária para adequar este tipo empresarial ao bom ordenamento jurídico brasileiro, colocando-a em consonância com os princípios constitucionais da livre iniciativa e o da igualdade, além do principio da preservação da empresa.

Todavia, a esperança que há atualmente é a ADI 4637, que ainda padece de julgamento perante o Suprema Tribunal Federal, a qual reconhecida a inconstitucionalidade dos cem salários, tornará a EIRELI um instrumento importante para o estimulo aos novos empreendedores brasileiros e ao consequente fortalecimento de nossa economia, atualmente tão fragilizad 


\section{REFERÊNCIA}

ALMEIDA, Amador Paes de. Manual das Sociedades Comerciais. 24. ed. São Paulo: Saraiva, 2012.

ASQUINI, Alberto. Profili dell'Imprensa. Rivista del Diritto Commerciale, v. 41, I, 1943. Tradução de Fábio Konder Comparato. Revista de Direito Mercantil. São Paulo: Revistas dos Tribunais, n. 104, p. 113-114, out./dez. 1996.

BOBBIO, Norberto. Da estrutura à função: novos estudos de teoria do direito. Tradução de Daniela Baccaccia Versani. Barueri-SP: Manole, 2007.

BULGARELLI, Waldirio. Tratado de Direito Empresarial. 29 ed. São Paulo: Atlas, 1995.

COELHO, Fábio Ulhoa. Manual de Direito Comercial. 20 ed. São Paulo: Saraiva, 2008.

MAMEDE, Gladston. Direito Empresarial Brasileiro - Empresa e Atuação Empresarial. 7. ed. São Paulo: Atlas, 2013.

NEGRÃO, Ricardo. Manual de Direito Comercial e de Empresa. 9 ed. Saraiva: São Paulo, 2012. V.1.

RAMOS, André Luiz Santa Cruz Ramos. Direito Empresarial Esquematizado. 1 ed. São Paulo: Método, 2011.

SILVA, José Afonso da. Curso de Direito Constitucional Positivo. 34 ed. São Paulo: Malheiros, 2001. 